\title{
Substrate feeding strategies in Pichia pastoris fed-batch cultivation processes: Analysis of key parameters influencing recombinant protein production
}

\author{
Ramon Ramon, Oriol Cos ${ }^{\dagger}$, Pau Ferrer ${ }^{\dagger}$, José Luis Montesinos and \\ Francisco Valero*
}

Address: Departament d'Enginyeria Química, E.T.S.E., Universitat Autònoma de Barcelona, 08193-Bellaterra (Cerdanyola del Vallès), Spain

* Corresponding author †Equal contributors

from The 4th Recombinant Protein Production Meeting: a comparative view on host physiology

Barcelona, Spain. 2I-23 September 2006

Published: 10 October 2006

Microbial Cell Factories 2006, 5(Suppl I):SI3 doi:10.II86/I475-2859-5-SI-SI3

(C) 2006 Ramon et al; licensee BioMed Central Ltd.

\section{Background}

An important number of heterologous proteins have been produced in the methylotrophic yeast Pichia pastoris using the methanol-inducible alcohol oxidase promoter [1]. Cultivation conditions and host physiology have an important impact on the final yields and productivities for heterologous protein production [2]. Recently, the effect of the Mut phenotype and gene dosage on the heterologous production of a Rhizopus oryzae lipase (ROL) in $P$. pastoris has been studied in fed-batch bioprocesses with a manual (off-line) methanol concentration control [4]. These studies demonstrated that variations of the residual methanol concentration influence drastically in the specific consumption and production rates. To avoid this problem a predictive control algorithm coupled with a PI feedback controller has been satisfactorily implemented [5].

This set-up has allowed for further analysis of several key parameters influencing heterologous protein production in $P$. pastoris fed-batch cultivation processes. In particular, the impact of i) the residual methanol concentration present in the culture broth and ii) co-feeding of a multicarbon substrate and methanol on process performance will be illustrated in a $P$. pastoris $\mathrm{Mut}^{\mathrm{s}}$ phenotype strain secreting a Rhizopus oryzae lipase (ROL) as a reporter protein.

\section{Results}

The effect of methanol concentration on heterologous ROL production during the fed-batch phase was analysed by performing cultivations at different methanol set points, ranging from 0.5 to $1.75 \mathrm{~g} \cdot \mathrm{L}^{-1}$. The maximal lipase activity (490 UA $\cdot \mathrm{mL}^{-1}$ ), specific yield (11236 UA . $\mathrm{g}^{-1}$ biomass $)$, productivity (4901 UA $\cdot \mathrm{L}^{-1} \cdot \mathrm{h}^{-1}$ ) and specific productivity (112 UA $\cdot \mathrm{g}^{-1}$ biomass $\cdot \mathrm{h}^{-1}$ ) were reached for a residual methanol concentration set point of $1 \mathrm{~g} \cdot \mathrm{L}^{-1}$. Notably, these parameters are almost 2-fold higher than those obtained with a manual control at a similar methanol set-point. The study of the consumption $\left(\mathrm{q}_{\mathrm{s}}\right)$ and production rates $\left(\mathrm{q}_{\mathrm{p}}\right)$ showed very different patterns for these rates depending on the methanol concentration set-point:

In all cultivations maximal $\mathrm{q}_{\mathrm{s}}$ values were obtained at the beginning of the induction phase; shortly after this point, $\mathrm{q}_{\mathrm{s}}$ started to exponentially decrease.

The evolution of the extracellular lipolytic activity was completely different depending on the residual methanol concentration at the fed-batch phase. In particular, when the methanol set point was set at $0.5 \mathrm{~g} \cdot \mathrm{L}^{-1}$, the $\mathrm{q}_{\mathrm{p}}$ reached a maximum of $340 \mathrm{UA} \cdot \mathrm{gX}^{-1} \cdot \mathrm{h}^{-1}$ at the beginning of the induction phase, followed by a sharp decrease to almost zero values after $20 \mathrm{~h}$ of induction. Since no proteolytic degradation of the product was observed, the exponential decrease in the product secretion rate was probably indicative that ROL synthesis had also stopped. In the fed- 
batch cultivation carried out at a set point of $1 \mathrm{~g} \cdot \mathrm{L}^{-1}$, the lipolytic activity values remained very low during a considerable period ( $20 \mathrm{~h}$ of induction phase); after this lag phase, a maximum $\mathrm{q}_{\mathrm{p}}$ value of $440 \mathrm{UA} \cdot \mathrm{gX}^{-1} \cdot \mathrm{h}^{-1}$ is reached after $40 \mathrm{~h}$ of induction phase, which was followed by an exponential decrease to values below $100 \mathrm{UA} \cdot \mathrm{gX}^{-}$ 1 . $\mathrm{h}^{-1}$ after $75 \mathrm{~h}$ of fed-batch phase. Again, neither extracellular protease activity nor important levels of cellular lysis were detected. The $\mathrm{q}_{\mathrm{p}}$ values during the fed-batch cultivation at a set point of $1.75 \mathrm{~g} \cdot \mathrm{L}^{-1}$ were kept rather constant throughout the bioprocess with significantly lower maximal (60 $\mathrm{UA} \cdot \mathrm{gX}^{-1} \cdot \mathrm{h}^{-1}$ ) and mean $\mathrm{q}_{\mathrm{p}}$ values. In this cultivation, extracellular lipolytic activity increased steadily until $110 \mathrm{~h}$. After this point, lipolytic activity slightly decreased by the effect of cellular lysis. However, obtained levels (150 UA $\left.\cdot \mathrm{mL}^{-1}\right)$ were similar to those obtained at the beginning of the induction phase when a methanol set-point of $0.5 \mathrm{~g} \cdot \mathrm{L}^{-1}$ was used $\left(137 \mathrm{UA} \cdot \mathrm{mL}^{-1}\right)$ in only 4 hours.

Overall, these results indicated that, although cell growth is genetically limited (the host strain is Mut ${ }^{\mathrm{s}}$ and, therefore, has a very limited methanol assimilation capacity), the synthesis and secretion rates are still greatly influenced by the residual methanol concentration (as expected from the observation that transcription levels from the AOX1 promoter are highest at methanol limiting concentrations [1]).

Since ROL expression has been shown to trigger the unfolded protein response [6], cells growing under carbon/energy limitation may not be able to sustain highest ROL production rates. To overcome this problem, we tested the effect of an additional, non-repressing, carbon source (sorbitol) on cell performance and heterologous protein expression and secretion during the methanol-fed induction phase. Remarkably, growth of Mut ${ }^{\mathrm{s}}$ cells in a batch cultivation using sorbitol and methanol as carbon sources showed that both substrates were co-assimilated simultaneously along the growth phase. Conversely, sorbitol and methanol were assimilated sequentially by wild type cells.

Hence, we performed replica fed-batch cultivations at a methanol residual concentration of $0.5 \mathrm{~g} \mathrm{~L}^{-1}$ and sorbitol below $2 \mathrm{~g} \mathrm{~L}^{-1}$ simultaneously fed. The maximum $\mathrm{q}_{\mathrm{p}}$ values reached at the beginning of the induction phase were similar (about $340 \mathrm{UA} \cdot \mathrm{gX}^{-1} \cdot \mathrm{h}^{-1}$ ). Although the $\mathrm{q}_{\mathrm{p}}$ decreased after this point, production rate stabilized at around 200 $\mathrm{UA} \cdot \mathrm{gX}^{-1} \cdot \mathrm{h}^{-1}$ until the end of the bioprocess. By using this strategy, the maximal lipolytic activity was 3.5 fold higher than in the fed-batch at $0.5 \mathrm{~g} \mathrm{~L}^{-1}$ of methanol as a single carbon source. The specific yield, productivity and specific productivity were also improved by 2.5, 2.6 and 2-fold, respectively.

\section{Conclusion}

The combined use of a P. pastoris Mut strain and the control of the residual methanol concentration during the fed-batch phase allow for the modulation of the ROL production rates. Since ROL expression triggers the UPR, cells growing under carbon and energy source limitation appear particularly sensitive to ROL production rates (highest process productivities are not achieved under methanol-limiting conditions i.e. when AOX1 promoter transcription levels are probably highest).

Notably, mixed carbon source co-assimilation seems to support cell's adaptation to the stress caused by ROL secretion, i.e. allowing for sustained specific secretion rates and boosting process productivities and yields.

\section{Acknowledgements}

This work was supported by a grant from the Spanish Program on Chemical Processes Technologies (CTQ2004-00300).

\section{References}

I. Lin-Cereghino J, Cregg JM: Heterologous protein expression in the methylotrophic yeast Pichia pastoris . FEMS Microbiol Rev 2000, 24:45-66.

2. Macauley-Patrick S, Fazenda ML, McNeil B, Harvey LM: Heterologous protein production using the Pichia pastoris expression system. Yeast 2005, 22:249-270.

3. Zhang $W$, Inan $M$, Meagher MM: Fermentation strategies for recombinant protein expression in the methylotrophic yeast Pichia pastoris. Biotechnol Bioprocess Eng 2000, 5:275-287.

4. Cos O, Serrano A, Montesinos JL, Ferrer P, Cregg JM, Valero F: Combined effect of methanol utilization (Mut) phenotype and gene dosage on recombinant protein production in Pichia pastoris fed-batch cultures. J Biotechnol 2005, I | 6:32|-335.

5. Cos O, Ramon R, Montesinos JL, Valero F: A simple model-based control for Pichia pastoris allows a more efficient heterologous protein production bioprocess. in press.

6. Resina D, Cos O, Gasser B, Mauer M, Valero F, Mattanovich D, Ferrer $\mathrm{P}$ : Analysis and engineering of bottlenecks in Rhizopus oryzae lipase production in Pichia pastoris using the mitrogen source-regulated FLDI promoter. in press.

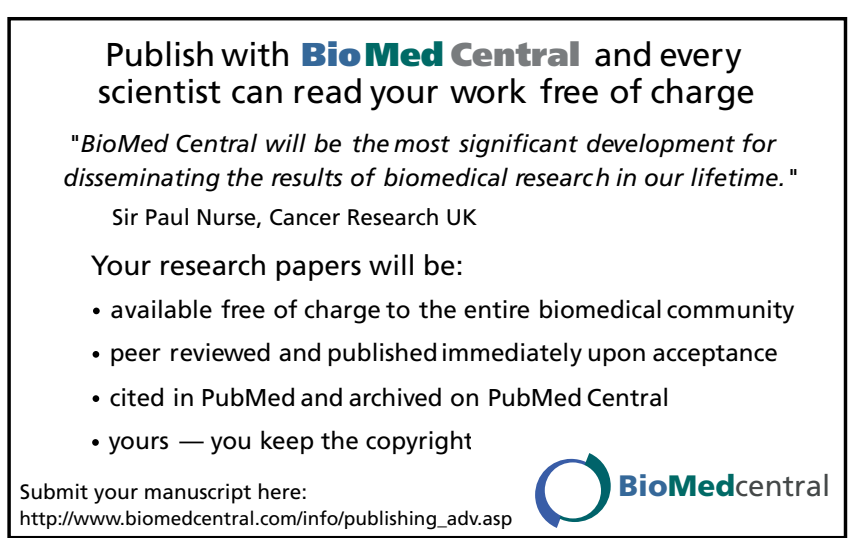

